\title{
Aging and Current Trends in Malaysia
}

\author{
Rose Jacob \\ Faculty of Social Sciences, Social Work Program, University of Science, Malaysia
}

\begin{abstract}
This paper is aimed to highlight the current trends, changes and issues affecting the elderly. Malaysia will experience Aging Population in 2030 when the population over 60 years old will be $15 \%$. The Malaysian population is experiencing an increase in life expectancy. Declining Fertility in late marriage, reduction in the family size, more women in the work force and urbanization are among other current changes. However, as the elderly continue to adjust to these changes and trends, there are more challenges which they face silently. Some of the elderly experience Depression which affects their inability to make accurate decisions and slows down their social and physical function. More adult care facilities and support groups needs to be initiated to look into the various problems of the elderly and help them overcome them.
\end{abstract}

Keywords Aging Population, Depression, Trends, Elderly

\section{Introduction}

This is a review based paper. In the World Assembly on Aging in Vienna in 1982, the United Nations had defined old age when a person is 60 years old and above. They are also referred to as the elderly or senior citizens. Aging Population is a phenomenon when the population of the elderly comprises more than $15 \%$ of the country's population. According to the United Nations Department of Economic and Social Affairs (UNDESA) in 2012, there would be 16\% of the elderly in 2030 and an increase to $22 \%$ in 2050 . In Malaysia, the rapid process of development has brought about demographic and epidemiologic changes. There is a marked decline in fertility and mortality thus increasing the life span of the elderly. Also, the proportion of the elderly is increasing. Aging population, the most significant change affecting the elderly in Malaysia needs to be addressed urgently and to be prepared to face this situation in the years to come.

The world is experiencing dramatically increased numbers of people living to an advanced old age. Often referred to as "the graying of the planet," this dramatic increase represents the most significant population shift in recent history (Obaid $\&$ Malloch-Brown, 2002). Malaysia too will experience this shift in 2030 when $15 \%$ of her population comprises of the elderly. According to United Nations, the elderly in Malaysia will double from $7 \%$ to $15 \%$ in 28 years in 2030 . Malaysia's population will then be $15 \%$ senior citizens as in Table 1 .

Table 1. Malaysia's Demographic Trend

\begin{tabular}{|c|c|c|}
\hline YEAR & $\%$ & REMARKS \\
\hline 2005 & 7 & \\
\hline 2010 & 8 & \\
\hline 2015 & 10 & \\
\hline 2020 & 12 & Aging Population \\
\hline 2025 & 13 & \\
\hline 2030 & 15 & \\
\hline 2035 & 18 & \\
\hline 2040 & 20 & \\
\hline 2045 & 21 & \\
\hline 2050 & 22 & \\
\hline
\end{tabular}

Source: Universiti Malaya: International Conference on Population Ageing: Issues and Challenges

\section{"Graying of the Planet"}

Malaysia's population has almost trebled over the past four decades, growing from a population of 7.4 million in 1957 to 20.7 million in 1995. Malaysia progresses on into the next millennium, between 1990 and 2020; its population is projected to increase by $80 \%$ that is, from 18.4 million to 33.3 million. At the same time its aged population is expected to increase by $211 \%$ that is from 1.05 million to 3.26 million. Frailty and dependency increase more rapidly after 70 years old. Not only are populations growing older, the old themselves are living longer. Thus aging in Malaysia will see the proportion of population aged 70 increasing from $2.21 \%$ in 1990 to $3.5 \%$ in 2020 . Its population age structure has also changed. The proportion of population aged 0-14 years had increased initially during the first two decades followed by a decline in the 1980s and 1990s. The proportion of elderly population has however shown a steady increase (Karim, 1997). 


\section{Increased Longevity}

The life expectancy as stated in 1980 is 63.5 for males and 67.1 for females (Statistics Department Malaysia).Through a research done in 2009, the life expectancy of Malaysians will be increased for males to 72.6 and females to 77.5. More sophisticated health care facilities and treatment, better prevention of infectious diseases and a marked improvement in the nutritional status has contributed to this increase. Health issues, both critical and non-critical have been managed well with the betterment of health care and medical facilities in both the public and private hospitals which ensures a satisfactory health care and better quality of life. This has enabled the elderly to be more independent and less dependent on others. Thus there will be prolonged death when there is prolonged pain and suffering. Improvements in health and living standards have resulted in increased life expectancy and the number of the older population.

Increased longevity implies increased vulnerability to diseases and disabilities, with consequent increased costs and greater burdening of caring for the elderly by the individual, family and the society compared to the past. Longer post retirement years affect older persons financially. So family and social adjustments are required as a result of this. This issue focuses on Alzheimer's diseases, an under diagnosed and under recognized condition that will fast pose challenges to caregivers and health care workers alike with tremendous financial and resource implications (Arokiasamy, 1999). As such, Malaysia needs to be equipped to meet this need from now as this has a long term implication for the government to have good health care for the elderly.

\section{Decreasing Fertility}

The Malaysian population is experiencing late marriage. The average age of marriage in 1980 is 23.5 years old which has seen an increase in 2000 to 25.1 years old. This is due to the higher level of education, more women in the work force, increase in urbanization, a better quality of life and an increase in the usage of contraceptives for family planning (Lamanna, M and Riedmann, A, 2006). The average size of a family was 5.2. in 1980. In 1991, this figure was reduced to 4.9 and in 2004 a further reduction to 4.5 . is recorded. The decline in fertility eventually leads to a higher proportion of older people in a population over time. The inability of families to cater to the high cost of living and education has an impact for families to shrink in size. With decreasing fertility comes fewer children, and hence a potentially diminishing 'reserve' of informal providers of support.

In Peninsular Malaysia, crude death rates declined from 12.4 per 1000 population in 1957 to 4.7 per 1000 population in 1990. Infant mortality rate (IMR) also fell from 76 per 1000 live-births to 12 per 1000 live-births and the expectation of life at birth increased from 57 years to 71.2 years over the same period. Fertility decline followed soon after and the crude birth rate (CBR) fell from 46 per 1000 population in 1957 to 28.4 per 1000 population in 1990 . Total fertility rate (TFR) also recorded a decline from 6.7 in 1957 to 3.3 in 1990 (Karim, 1997). The change from a situation of high mortality and high fertility to low mortality and subsequently low fertility has been described by Notestein as 'Demographic Transition' (Karim, 1997).

\section{Economic Growth}

Rapid development has transformed the mainly rural agricultural society to an increasingly urbanized industrial society. The percentage of population employed in the agricultural sector has decreased from $52 \%$ in 1970 to $26 \%$ in 1990, whilst female labor force participation has increased from $36 \%$ in 1957 to $47 \%$ in 1991 (Leete, 1996). Rapid economic growth saw the country's Gross National Product (GNP) per capita increased from rm 1,106 in 1970 to rm 9,786 in 1995; and the incidence of poverty among Malaysians reduced from $16.5 \%$ in 1990 to $8.9 \%$ in 1995 . Rapid expansion of educational facilities has increased literacy rates and decreased educational disparities between males and females.

\section{Disproportion between Males and Females}

Disproportion between the numbers of males to females also increases with aging. Projected increases between 1990 and 2020 in the number of aged persons in Malaysia are 1.01 million for males and 1.20 for females. The sex ratio (number of men per 100 women) will decrease from 90.1 in 1990 to 85.8 in 2020 . Thus there will be an increasing predominance of women among the aged population in Malaysia (Karim, 1997). The notion of the feminization of old age, a concept which depicts the demographic reality that it is almost universally the case that women live longer than men, although in various parts of the world this difference is now decreasing. While women may still have 'the edge' over men in terms of the number of years they live, they are more likely to encounter problems of social isolation, poverty, poor health and other forms of deprivation (Arber and Ginn, 2005). Women are traditionally the main providers of care for the disabled, young and the elderly. However the longer living females do not necessarily have a longer period of good health, as disabilities are common among them with longer periods of chronic health problems (Arokiasamy, 1999).

Increased mobility and participation of women in the labor force, as well as the changing family structure will have a great impact on the extent families can participate in the care of the elderly. Thus if the family is expected to be responsible for the care of the elderly in the future, greater support and flexibility should be given to women to ensure that they can play the many roles that are expected of them and at the same time contribute to the labor force. 
Feminization of aging leaves many women alone in old age or caring for their older partners, which creates challenges as their health declines. Traditional practices relating to widowhood may result in violence and abuse of older women, posing a threat to their health and well-being. Older women living alone may not know where or how to negotiate access to health care and welfare services on their own. Further, while women typically live longer, they are more likely than men to experience disadvantages in access to education, food, meaningful work, health care and social security, and political autonomy over their lives. These cumulative disadvantages mean that older women are more likely than older men to be poor and to face disabilities and social disadvantage (World Health Organization, Fact Sheet, $26^{\text {th }}$ July 2014). Women need to be more independent.

\section{Rural-Urban Migration}

The percentage of population in urban areas has increased from $24.5 \%$ in 1957 to $50.8 \%$ in 1990 . The rapid migration of younger populations to urban areas leads to the isolation and marginalization of the elderly. However as the urban workers age, the future will see the aged predominantly in urban areas. Also, many young people work in industries which are located mainly in urban areas and usually away from their family homes. Rural-urban migration becomes inevitable causing a breakup in the extended family structure. This migration of young persons from rural areas has aggravated the aging of the population in rural communities. The older persons there would be left to fend for themselves which includes seeking and utilizing health care services (Arokiasamy, 1999).

More and more people are moving from the countryside to live and work in the big towns and cities. Thus Malaysia is getting more urbanized. There are better educational and work opportunities in big towns and cities like Kuala Lumpur, Penang and Johor Bahru. Thus, industrial development in the Klang Valley, the Bayan Lepas area of Penang Island and around Iskanar Johor Baru has been accompanied by migration and population increase. Thus, we witness the phenomenon of "emptying out" of the cities during major festivals such as Hari Raya Aidil Fitri and the Chinese New Year. As for Johor Bahru, the availability of higher-paying jobs in nearby Singapore has also been an important factor in its population increase. Malaysians who live in Johor Baru can commute daily to work in Singapore and further their education there too.

\section{A Human Right's Based Approach on Health}

Health is a basic human right for all, including older people. Realization of the right to health requires an environment that enables everyone to be as healthy as possible. Phenomena such as ageist attitudes, neglect, abuse and violence against older people in various forms contribute to the violation of their right to health. Leadership and strong actions are needed to move away from negative images of ageing to the view that older people are valuable assets for their families, communities and society as a whole (World Health Organization, Fact Sheet, $26^{\text {th }}$ July 2014).

As a result of demographic transition, with increasing numbers of people surviving until adulthood, an increasing proportion of the population is at risk of non-communicable, chronic health problems. This is associated with a change in the morbidity and disease pattern from one of mainly infectious diseases to one where chronic degenerative and non-communicable diseases predominate. This process is termed 'Epidemiologic Transition'. As Malaysia undergoes epidemiologic transition and ageing, cardiovascular diseases, diabetes mellitus, cancers and injuries have already emerged to be important causes of mortality and morbidity in the population (Lim, 1993). For the elderly, increased age would mean more complexity of chronic health issues and higher usage of specialized health services which would incur more expenditure. Thus, although tomorrow's elderly population will certainly be larger than todays, the demographic and epidemiologic transition will not remain constant.

There is a growing concern of the fewer number of children per couple which affects availability of caregivers and for financial support. With increased participation of members of the nuclear family in the labor force, especially in the urban areas, this may result in older person being left alone in the home. In the event of hospitalization or chronic illness this may mean one member of the family having to stop work to look after the older person or the latter having to be sent to a nursing home.

The prevalence of chronic illness among the elderly respondents was high $(60.1 \%)$. This finding corresponded to other studies, which found that $50-60 \%$ of the elderly had chronic illnesses (Shahar, 2001). In the study by Shahar, the major chronic illnesses reported among the elderly were joint pains $(45.0 \%)$, followed by hypertension $(22.9 \%)$ and respiratory problems $(15.1 \%)$. Salleha also reported that $15.1 \%$ of the elderly had problems in one or more ADL functions.

In a study conducted on Physical and Mental Health Problems of the Elderly in a Rural Community of Sepang, Selangor, the results showed that there were a higher percentage of females compared to males among the elderly respondents. There was also a much higher percentage of widowhood among the females compared to males. These findings could be due to the comparatively higher longevity of life in females. As expected, a high proportion of elderly people live with their families. This finding corresponded to another study in Malaysia which found that $90 \%$ of the elderly respondents in rural communities lived with their families (Shahar, 2001). Nearly half of the elderly respondents had received no education. In her study, Shahar 
explained that the low percentage of educated elderly was due to the lack of educational opportunities, particularly in rural areas.

\section{Health Concern - Depression}

Depression is not to be seen as part of aging. The changes that often come in later life which includes retirement, the death of loved ones, increased isolation, chronic health issues, finance and others can lead to depression. Depression prevents you from enjoying life like you used to. But its effects go far beyond mood. It also impacts your energy, sleep, appetite, and physical health. However, depression is not an inevitable part of aging. Depression is not to be accepted as a normal process of aging. Depression is often misunderstood and many times not recognized. This issue is a leading health care concern for the elderly and the family. It is a hidden mental disorder which affects the self-esteem of the elderly. When the elderly think of themselves as helpless and hopeless, they think of themselves as a failure. Symptoms of depression must be identified so that depression can be avoided and treated accordingly. Family support is vital when the elderly goes through depression. On the other hand, the Ministry of Health needs to train more medical personnel on the treatment for depression to cope with the increase in number.

In a research done on depression among elderly patients in a primary health care clinic in Malaysia, the prevalence of depression in the elderly attending Klinik Kesihatan Butterworth in Malaysia was $18 \%$. The findings of the present study are consistent with other studies which reported the range of depression in primary care settings were from $5 \%$ to $37 \%$. Elderly females were found to be almost three times more depressed compared to elderly men. This could be explained by the fact that elderly women had frequently lost their spouses and were widowed. In developing countries like Malaysia, the situation is even worse as most elderly women are financially dependent on their spouses and are from the lower socio economic group (Sherina, 2003).

\section{Discrimination}

According to Robert N Butler, "Prejudice against age is a prejudice against everyone". Butler was the founding director of the federal Government's Institute of Aging. His bigger impact on the lives of older Americans was his coining of the term "ageism". He used this to describe prejudice, discrimination and abuses committed against the elderly in a 1969 article which he wrote for the Gerontologist, a medical journal. Butler saw a better way. He championed the notion that older people had valuable insights and experience to contribute to society, and that if afforded the opportunity, they could continue to lead productive, fulfilling lives. Ageism is too often tolerated in societies across the world. Discrimination on the basis of age is often combined with other forms of discrimination, on the grounds of gender, race and ethnicity, religion, disability, health or socio-economic conditions, job opportunities and promotions, among others negatively affecting the enjoyment of the full range of human rights of older persons.

\section{Proposals to Cope with the Current Trends}

a) Financial assistance must be given to the elderly who are in need so that they need not depend on anybody and can be independent. This helps to alleviate their low standard of living and give them a better quality of life. Also abuse can happen when an elderly is totally dependent on another.

b) There must be more Support Groups which are available and reachable to the elderly for specific diseases for example Depression, Parkinson's, Alzheimer's, Cancer and others. Information regarding these Support Groups should be given to the elderly at hospitals and other centers.

c) More Adult Day Care Facilities should be set up to prevent the elderly living in isolation and to minimize the burden of the caregivers.

d) An Old Persons Act to cater for the specific needs of the elderly for example health care, abuse, violence and discrimination must be tabled and approved to a better quality of life for the elderly.

e) To have an increase of specialists in geriatrics in the health care profession. In the geriatric care of older persons, the goal is not necessarily to cure them but to increase their healthy years of life. However, the rewards in geriatrics may not be as glamorous as in other specialties.

f) There is also a need to assist and support caregivers taking care of the elderly in their own homes and/or nursing homes. Training for these caregivers will ensure that better quality care is provided for the elderly. The care givers also require motivation, support and assurance from time to time.

\section{Conclusion}

As Malaysia moves towards a developed nation status, aging population is inevitable. At the same time, Malaysia is experiencing a demographic and epidemiologic transition among the elderly. There is an utmost need for health policy on aging available to all the elderly. Quality health services which are available and affordable to the elderly will prevent pain and suffering, further disease and disability and would ensure comfort to the elderly. Accurate statistics on the mortality and morbidity of the elderly using a scientific approach must be recorded and updated constantly. Further research in the diseases, health problems of the aging men 
and women and other related areas of the elderly should be given serious attention. All these improvements require a multi-disciplinary approach. The demographic and epidemiologic trends include all of us directly which raises an urgent level of awareness, concern and action. Some may be experiencing these trends now while for others these trends would become a reality in the future.

\section{REFERENCES}

J.T. Arokiasamy (1999). Malaysia's Ageing Population: Challenges in the New Millennium. Med J Malaysia Vol 54 N0 4 Dec 1999.

Government of Malaysia, Seventh Malaysia Plan 1996-2000, Kuala Lumpur. National Printing Department, 1996.

H. A. Karim (1997). The Elderly in Malaysia. Med J Malaysia Vol 52 No 3 Sept 1997.

Salleha K. A Community Based Study on the Profile of Functional disability among Elderly in Sepang. BSc Thesis. Universiti Putra
Malaysia; 2001(Unpublished)

Shahar S, Earland J, Abd Rahman S. Social and Health Profiles of Rural Elderly Malays. Singapore Med J. 2001: 42 (5):208.

Sherina Mohd. Sidik (2003). Factors Associated with Depression among Elderly Patients in a Primary Health Care Clinic in Malaysia. Asia Pacific Family Medicine 2003; 2:148-152.

Sowers, K. M., \& Rowe, W. S. (2006). Social work and social justice: From local to global perspectives. Belmont, CA: Thomson Learning.

Lim K. G. (1993). A Review of Diseases in Malaysia. Pelanduk Publications, Malaysia.

Notestein F W (1953). Economic Problems of Population Change. In Proceedings of the Eighth International Conference of Agricultural Economics, London. Oxford University Press.

Obaid, T. A., \& Malloch-Brown, M. (2002). Joint statement to the Second World Assembly on Ageing. April 8-12, 2002, Madrid, Spain.

Wiles, J (2005). Conceptualizing place in the care of older people: the contributions of geographical gerontology. International Journal of Older People Nursing in Association with Journal of Clinical Nursing. 